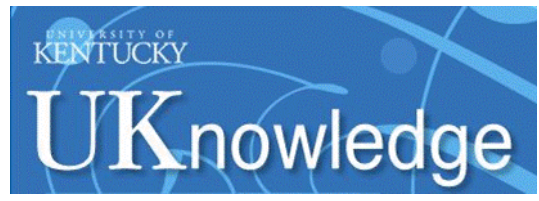

University of Kentucky

UKnowledge

August 1997

\title{
Psychic Unity Constraints upon Successful Intercultural Communication
}

James M. Donovan

james.donovan@uky.edu

Brian A. Rundle

Follow this and additional works at: https://uknowledge.uky.edu/law_facpub

Part of the Anthropology Commons

Right click to open a feedback form in a new tab to let us know how this document benefits you.

\section{Repository Citation}

Donovan, James M. and Rundle, Brian A., "Psychic Unity Constraints upon Successful Intercultural Communication" (1997). Law Faculty Scholarly Articles. 431.

https://uknowledge.uky.edu/law_facpub/431

This Article is brought to you for free and open access by the Law Faculty Publications at UKnowledge. It has been accepted for inclusion in Law Faculty Scholarly Articles by an authorized administrator of UKnowledge. For more information, please contact UKnowledge@lsv.uky.edu. 


\section{Psychic Unity Constraints upon Successful Intercultural Communication}




\title{
PSYCHIC UNITY CONSTRAINTS UPON SUCCESSFUL INTERCULTURAL COMMUNICATION
}

\author{
JAMES M. DONOVAN and BRIAN A. RUNDLE
}

Miscommunication is accepted as an inevitable feature of intercultural communication. The majority of writings implicitly assume that these failures are the consequence of lack of competencies on the part of the interactants. Alternatively, at least a small percentage of these failures may be the result of the language itself. Psychic unity, the anthropological concept of a fundamental biological homogeneity of man's mental life, is the unexamined property which makes communication of any sort possible. However, the details of psychic unity, especially as they pertain to category construction, predict that communication must fail under conditions which are both predictable and articulable.

Intercultural communication, which first found its disciplinary voice within the work of anthropologist Edward T. Hall, has been defined as a 'transactional, symbolic process involving the attribution of meaning between people from different cultures' (Gudykunst and Kim, 1984, p. 14). Central to the study of this process is the realization that cultural differences present obstacles beyond those present in every act of interpersonal communication. For instance, Gudykunst and Kim (1984, p. 30) suggest that all participants bring to the exchange cultural, sociocultural, psychocultural, and environmental backgrounds which interact to shape the communication event. Since these backgrounds and contexts are inherently individual, the simple fact that they differ necessarily leads to communication biases, compelling the conclusion that a universal feature of communication events is that they all fail to one degree or another. 'It is impossible,' they tell us, 'for any two people to communicate without any misunderstanding' (p. 191).

Lapses during intercultural communication episodes are thereby routinely expected, a statement few would find controversial. The difficulty comes in trying to ascertain first the source of those gaps or problems, and second, the possibility of correcting or resolving them. A large quantity of research in intercultural communication is what Coupland et al. (1991, p. 13) refer to as 'Level III,' wherein 'miscommunication takes on implications of personal inadequacy and therefore, perhaps, blame.' The source of failure here is the individual participant, but for whom it is assumed that proper education, sensitivity, and/ or experience can bridge these gaps, achieving effective intercultural communication. The goal of this type of intercultural communication research is to 'minimize' the misunderstandings (Gudykunst and Kim, 1984, p. 191) by maximizing speaker 'competence' (e.g. Wiseman and Koester, 1993). This outlook has been uncomplimentarily labeled the 'Pollyanna perspective' (Coupland et al., 1991, p. 1).

Correspondence relating to this paper should be addressed to Dr James M. Donovan, Tulane Law Library, 6329 Freret, New Orleans, LA 70118-5600, U.S.A. 
For his part, Hall understood that "culture controls behavior in deep and persisting ways, many of which are outside of awareness and therefore beyond conscious control of the individual' (1959/1981, p. 25), and therefore 'all that one ever gets from studying foreign culture is a token understanding" (pp. 29-30), "no person ever learns another's language perfectly' (Campbell, 1964, p. 317). In other words, cultural differences generating miscommunication are very unlikely to ever be completely overcome without 'going native.'

John Wengle (1988) offers some interesting thoughts on this issue for anthropologists. He believes that 'the notorious difficulty' some fieldworkers have in learning the native language is partly psychologically based. Clinging to one's own native tongue helps the anthropologist to stabilize his or her sense of personal identity, which is inevitably threatened by the experience of immersion during fieldwork (p. 144). In these terms, 'going native' is akin to the 'Secondary identification [which] enables the anthropologist to narrow, for a time, the vast gap of cultural experience separating him from his subjects' (p. 159). So while the types of cultural learning which would be necessary to minimize miscommunication are possible, it is at best a rare accomplishment which entails at least one party to the exchange having experienced the disintegration and reconstruction of his or her sense of self. Not everyone survives the attempt in good mental health. And in some important senses the problems of intercultural communication have only been shifted further back by the anthropologist having assumed the native perspective. Two cultures are no longer communicating across a breach; rather, one party has leapt across that chasm. True intercultural communication will have to wait until the researcher returns home to relate what he or she has learned.

The implication of this study of culture shock is that Level III research cannot completely or routinely resolve the problems of intercultural communication. Even while Hall's caution and Wengle's analysis refute the likely success of Level III analyses, they nonetheless accept the Level III implications that failure to communicate is a practical consequence of lack of skill of some kind on the part of one or more of the interlocutors. They pay far less attention to Level I sources of miscommunication, wherein 'routine discourse is intrinsically constrained through (a) limited code and channel capacities; (b) the interplay between linguistic meaning and context; and hence (c) the need for cognitive heuristics in both encoding and decoding' (Coupland et al., 1991, p. 12). Rather than the lack of ability or talent which could conceivably be largely compensated for by training or exposure, Level I difficulties arise from the innate 'fallibility of human thought and action.' If communication success at Level III is a question of practical ability, at Level I perfect, and sometimes even adequate communication is ruled out as a theoretical possibility even for perfectly skilled, fully assimilated interactants.

We agree that the very nature of the human mind puts constraints upon communication events, even if we would not necessarily characterize that nature as 'fallible.' The goal of this article is to propose just why this should be the case. Why can I not, even in theory, be assured that the thoughts in my mind can be communicated to you?

The answer, we argue, is that that which makes communication possible also necessarily makes communication problematic. The anthropological concept of the psychic unity of mankind is where we must look.

\section{Psychic unity of mankind}

The inevitable failure of communication is built upon the argument that each individual possesses a unique set of distorting conceptual filters through which messages must pass 
(Child, 1950; Gass and Varonis, 1991). This relativistic position opens the way for a nigh infinite amount of variation, some combinations of which would be expected to differ so radically that they remain mutually unintelligible despite one's best efforts.

However, the field also holds that this distortion can be overcome, that in fact intercultural communication is always possible to some significant degree. (Relevant here would be Wittgenstein's denial of the possibility of a private language, that is, 'the possibility of a language that is necessarily private, one that only one person [or, by extension, group of persons] could understand' (Alston, 1993, p. 53); as well as George Herbert Mead's "position that "you cannot say anything that is absolutely particular; anything you say that has meaning at all is universal" ' (Leaf, 1979, p. 202).) This second assumption can only be entertained in a theoretical environment in which something operates to constrain filters from assuming all logically possible variants. Thus Lenneberg can marvel that,

although language families are so different, one from the other, that we cannot find any historical connection between them, every language, without exception, is based on the same universal principles of semantics, syntax and phonology. All languages have words for relations, objects, feelings and qualities, and the semantic differences between these denotata are minimal from a biological point of view.... Thus,...the basic skills for the acquisition of language are as universal as a bipedal gait (Lenneberg, 1967, p. 68).

Gudykunst and $\operatorname{Kim}(1984$, p. 164) recognize that human cultural variation is built upon a commonality of some kind, observing that 'Most cross-cultural researchers enthusiastically assume a universality of a common core of human culture while acknowledging the enormous variation in specifics.' Cultural variability is thus significantly smaller than would be expected without the constraining influence of some inherently human property.

Campbell (1964) argues that this assumption of basic similarity is necessary to make sense of any search for variety. 'In the end, it is because in great bulk we perceive alike (respond alike) that we can note small differences in perception. The total context of agreement provides the firm platform from which we can note a particular, localized discrepancy.... [Were] a culture to perceive in a radically different way, we could not confirm communication and hence could not ascertain perceptual differences' (p. 325).

The perception of a basic similarity of cultures has been part of the anthropological mindset since the field's inception, even if, as Brown (1991) argues, the intellectual foundations to explain that similarity have suffered neglect in recent decades. Still, anthropologists 'rely upon [these similarities] at every turn in order to do their work' (p. 154). Early giants such as Tylor observed that 'similar arts, customs, beliefs [and] legends are found in several distant regions, among peoples not known to be of the same stock' $(1878 / 1964$, p. 3), while Frazer depended upon the relative uniformity of culture to prop up his version of the comparative method used in his voluminous The Golden Bough.

Intercultural communication, at least as represented by Gudykunst and Kim's seminal text, parts company with anthropology over to what this perception of cross-cultural similarity is to be attributed. Continuing with the passage begun above, the authors conclude that:

The basic explanation for the universality seems to be in the intrinsic nature of humans as social animals and in their capacity to use symbols and to develop a speech community. While the detailed manifestations of such human social activities vary from culture to culture, all humans need, and have the capacity, to communicate within their social and physical environment in one form or another (Gudykunst and Kim, 1984, p. 164). 
But man as 'social animal' does nothing to explain intercultural communicability. For while it is certainly true that all humans develop speech communities prompted by the need to 'communicate within their social...environment,' nothing can be concluded from this about the prospects for communicating between these communities. This view lacks anything to restrict the range of variability of real languages so that no two become irredeemably unintelligible.

Historically, anthropology has offered a different explanation. Bastian, partaking of an intellectual tradition which dates back to at least Periclean Athens, argued that,

\footnotetext{
The physical unity of the species man has been anthropologically established, and as a consequence we now look for the psychic unity of mankind. The psychic unity of social thought (collective representations) underlies the basic elements of the body social. The world over we will find a monotonous sub-stratum of identical elementary ideas, identical in spite of local variations. These few elementary ideas exist in all natural savage conditions and also under the artificial veneer of every civilization; they are indeed those seminal ideas from which civilizations have grown (Bastian, quoted by Koepping, 1983, pp. 175-176).
}

Both cross-cultural similarities and variations are accounted for in this scheme as being the elaboration of a limited set of basic social categories. Pertinent to our study here is the way the concept of psychic unity is derived from mankind's biological uniformity.

Any relationship which holds true regardless of the sociocultural environment must be attributed to the only thing which all humans have in common, namely, the biological endowments characteristic of the species. (This does not mean that if a trait varies, it is necessarily wholly cultural. Brown $(1991$, p. 103, n. 6) points out that if 'it varies in a regular pattern, it may well not be cultural' due to 'phylogenetic facultative adaptations.' But this case is more complicated, and we will therefore be restricting our attention to the case of cross-cultural invariants, which are certainly noncultural.)

Thus, if, as Sapir (1949, p. 153) states, 'a language is so constructed that no matter what any speaker of it may desire to communicate, no matter how original or bizarre his idea or fancy, the language is prepared to do his work,' and if, despite the development of a specific language in a specific context and the theoretically infinite variety of structure which language could adopt, translation in some general sense can occur between any two languages, then we are forced to accept two entailments.

First, that there exist fundamental human universals in language development whose operation allow translatability, and second, given the presence of these universals despite the cultural variation, that these same universals must be a product of material (physical, biological) as opposed to sociocultural causes, which in their turn are responsible for the variations upon this common repertoire.

Thus we arrive at our first conclusion. The working axioms of the practice of intercultural communication can only be justified if they are intuitively built upon the foundations of the assumption of the psychic unity of mankind. That psychic unity we would define as referring to those categories of mental life which human beings hold in common by virtue of their biological heritage arising from membership within the same species, and which are also unique to that species. Within this context, the biological substrate which makes human language possible is an important component of psychic unity, and the one upon which we will focus.

The idea that language itself has biologically established parameters which limit its variability is not new. Among linguists, Noam Chomsky's (1972) universal grammar and Derek Bickerton's (1984) language bioprogram hypothesis are but two articulations of this approach. We should not be surprised, therefore, to find evidence of its presence 
within the field of intercultural communication since its very inception. (The details of what aspects of language are innately endowed are still vague, but challengers to aspects of Chomsky's model have arisen; see Bower (1997) for a brief overview of this debate.)

Edward T. Hall's The Silent Language, published in 1959, is considered the first work in the field. Hall, with George L. Trager, attempted to discover the building blocks of culture (referred to by Hall as 'isolates') and a method of analyzing them to discern their effects on communication. In doing so, he concluded that he would have to 'tie these isolates into a biological base so they could be compared among cultures' (Hall, 1959/1981, p. 27). Furthermore, Hall writes that, in trying to discover how cultures differ and how these differences can be explained, he realized that:

culture is bio-basic-rooted in biological activities. Infra-cultural is the term which can be given to behavior that preceded culture but later became elaborated by man into culture as we know it today. [By] going back to infraculture it is possible to demonstrate that the complex bases - mainly biological - upon which human behavior have been built were laid down at different times during the history of evolution. Trager and I also reasoned that the number of infra-cultural bases were probably very few and that they probably led to very different types of activities, things that on the surface bore little or no apparent relationship to each other (Hall, 1959/1981, p. 37).

Given such a statement, it is unsurprising to learn that Hall allows for the existence of a psychic unity (pers. comm. to Rundle, 1992).

Our interests, however, do not lie merely with the intellectual archaeology of disinterring and revealing the artifact of psychic unity within the ground of intercultural communication. More importantly, having explicitly identified psychic unity, and especially its linguistic component, as the given which generates the expectations of the field, we wish to examine the concept more closely. If psychic unity as thus described makes communication possible, further prodding reveals that it also places a ceiling on the expected success of a given communication exchange.

The goal, therefore, will be to show that a consequence of founding intercultural communication upon an assumption of psychic unity necessarily entails that, even in an ideal world, communicability is a variable quantity. While psychic unity guarantees that all languages can communicate on most topics, it also renders some things more difficult to talk about, and precludes meaningful discussion of others altogether. As such, psychic unity is the biological mechanism effecting the radical subjectivity described by McTear and King (1991, p. 198).

\section{Psychic unity and categorization}

The presence of the assumption of psychic unity within the field of intercultural communication was detectable because of the expectation that 'misunderstandings' can be 'minimized.' The implicit optimism within the discipline that in an ideal world all such misunderstandings might be corrected is also a heritage of the history of psychic unity. However, it is not psychic unity as we understand it today, but instead that of the nineteenth century unilineal evolutionists such as Tylor and Frazer.

In this archaic model, all human culture is but the unfolding of an inevitable developmental process. Such differences as are perceived are, on the one hand, relatively uninteresting when compared to the similarities, and, on the other, can be interpreted as being but the lack of development on the part of the (other) culture, or due to the incidental effect of historical accident and again, relatively uninteresting. 
This interpretation of culture encouraged a direct mapping from one culture to another. To understand something in one culture, one dissected the phenomenon in an altogether different sociocultural setting, and then generalized freely back to the original problem. Since the examples were understood to be but two products of a unitary and inevitable process, each instance was immediately 'translatable' from one to any other.

This was the explicit logic used by James Frazer in his massive The Golden Bough:

if we can show that a barbarous custom, like that of the priesthood of Nemi, has existed elsewhere; if we can detect the motives which led to its institution; if we can prove that these motives have operated widely, perhaps universally, in human society, producing in varied circumstances a variety of institutions specifically different but generically alike; if we can show, lastly, that these very motives with some of their derivative institutions, were actually at work in classical antiquity; then we may fairly infer that at a remoter age the same motives gave birth to the priesthood of Nemi. (Frazer, 1890/1981, p.3).

This charmingly naive perspective was explicitly justified by the understanding of psychic unity which Frazer had inherited from Bastian and Tylor: 'For recent researches into the early history of man have revealed the essential similarity with which, under many superficial differences, the human mind has elaborated its first crude philosophy of life' (Frazer, $1890 / 1981$, p. 3 ; note how the very sentence invokes the title of Tylor's book).

Although Frazer was attempting to understand religion, and our focus here is on language, the logic used in both projects is identical: because the disparate members of a class - for Frazer, religious observances, for intercultural communication, speech acts are assumed to derive from a single source which we have termed the "psychic unity of mankind,' the default expectation is that all members of the class bear a genetic relationship which permits a transposition of one to the other.

Anthropology at the turn of this century rejected the unilinear approach to cultural development, and thereby the specific articulation of psychic unity which supported it. Culture traits which appear to be similar are no longer be assumed to be similar in fact. In a tour de force which almost single-handedly demolished this line of investigation, Franz Boas observed that

The theory of parallel development [unilinear evolutionism], if it is to have any significance, would require that among all branches of mankind the steps of invention should have followed, at least approximately, in the same order, and that no important gaps should be found. The facts, so far as known at the present time, are entirely contrary to this view (Boas, 1911, p. 182).

If the supposition that all cultures have evolved along a single continuum is false, then the assumption that all traits seen to be similar are homologous must also be false, or at least must justify itself on some other principle.

This change in anthropological paradigm initiated repercussions within American anthropology which persist to this day. Historical particularism is now the traditionally accepted mode of scholarship, and what explicitly cross-cultural research as is today conducted requires that the comparability of the selected culture traits be demonstrated rather than assumed (cf. Armer, 1973).

Obviously, the understanding of psychic unity which warranted unilinear comparative research could not have survived this attack. A concept which had originally been understood to explain the products of cultural development was now restricted to account for the process without reference to the outcome of the application of that process. Using a mathematical image, we could say that if a particular culture trait was the sum of an algorithm, psychic unity now provided the formula which specified the relevant variables and their relationship, while other factors - for instance, cultural inheritance, current 
environment, accident - determined the specific value of the variables. Brown (1991, p. 81) discusses the works of Robin Fox which also argues a distinction between process universals and 'substantive' universals; cf. Gudykunst and Ting-Toomey (1988, p. 138). The question then becomes, What kinds of formulae for language do humans possess by virtue of biological endowment?

We have already noted that both linguistics generally, as well as intercultural communication, allow for a biological substrate to human language. Our attention narrows here to the pivotal role of categories and the role they play in language. Gudykunst and Kim (1984, p. 84) remark that 'The human brain requires categories in order to process information and think. Categorization cannot be avoided; it is necessary for an orderly life.' While these authors admit to a universal 'urge' to categorize on the part of humans, they do not explicitly address whence the categories come, and whether all categories are constructed of the same 'stuff' or by the same rules.

Psychic unity suggests that, not only do humans categorize, but also that the process of category formation is not completely arbitrary. Contemporary research into the problem substantiates this position. Within a language, categories can be viewed as being constructed around one of two criteria: perceptual salience, where the phenomena being categorized impinge upon the human consciousness by virtue of the species' biological equipment, and experiential salience, where categories are constructed out of the environment according to the needs and interests of the speakers.

Categorization in early models entailed superimposing conceptual 'breaks' upon an allegedly continuous array of environmental stimuli. Perceptual salience holds that some of these stimuli which are logically or even physically continuous are less so when they interact with the sensory interfaces of the human animal. Best studied of this type is color.

The original report in 1969 by Berlin and Kay (1991, p. 109) concluded that 'Our essentially linguistic investigations have led, seemingly inescapably, to the conclusion that the eleven basic color categories are pan-human perceptual universals.' Not physical, as in optical universals; but rather perceptual universals. A regular cottage industry arose around this seminal study, as workers tried either to attack or refine it, such as the contribution by MacLaury (1992). Barnes (1987, p. 126) concludes that 'Berlin and Kay's hypothesis has not withstood the challenge of scholarly criticism as well as writers sometimes suggest,' at least as pertains to its cultural implications. But the original authors, in a new preface for the paperback edition of their study, offer this summary of the current state of knowledge:

\begin{abstract}
While the accumulation of new data has brought substantial changes to our view of the details of the developmental sequence as originally represented in this text, the two principal findings of the original study...have stood the test of these new data: (1) there are substantive universal constraints on the shape of basic color lexicons - systems of color naming do not vary randomly or capriciously across languages but are constrained to a small number of possible types; and (2) basic color lexicons change type over time by adding basic color terms in a highly constrained, though not mechanically predictable, manner (Berlin and Kay, 1991, p. v).
\end{abstract}

This model, however, accounts for relatively few of the categories possessed by people. Other types of categories will therefore be built upon different inputs, although the results will be structured identically.

For those categories which probably have a physiological basis such as colours, forms, and facial expressions of basic human emotions, prototypes appear to be stimuli which are salient prior to formation of the category, whose salience, at the outset, determines the categorical structure of those domains. For categories of concrete objects, however, prototypes would appear to develop through the same principles, such as maximization of cue validity, as those governing the formation of the categories themselves (Rosch, 1977, p. 35). 
Two concepts are introduced here. The first, cue validity, is defined by Rosch as

a probabilistic concept; the validity of a given cue $\mathrm{x}$ as a predictor of a given category $\mathrm{y}$ (the conditional probability of $y / x)$ increases as the frequency with which cue $x$ is associated with category $y$ increases and decreases as the frequency with which cue $x$ is associated with categories other than $y$ increases (Rosch, 1977, p. 29).

The second, the basic level, is

\begin{abstract}
the level of abstraction at which the organism can obtain the most information with the least cognitive effort. That is, to categorize a stimulus means to consider it, for purposes of that categorization, not only equivalent to other stimuli in the same category but also different from stimuli not in that category.... [In] so far as categorization occurs to reduce the infinite differences between stimuli to behaviourally and cognitively usable proportions, it is to the organism's advantage not to differentiate stimuli from other stimuli when that differentiation is irrelevant for the purposes at hand. The basic level of classification, the primary level at which cuts are made in the environment,...is the most general and inclusive level at which categories can delineate realworld correlational structures (Rosch, 1977, p. 29).
\end{abstract}

These two concepts, basic level and cue validity, are interrelated.

In the domain of both man-made and biological objects, there occur information-rich bundles of perceptual and functional attributes that form natural discontinuities. If basic objects (e.g. chair, car) are the most inclusive level of categorization at which there can be many attributes common to all or more members of the category, basic objects will, thereby, be categories at the level of abstraction for which cue validities are maximized (Rosch, 1977, p. 29).

'The point,' as Lakoff $(1987$, p. 50$)$ says, is that 'the level of categorization is not independent of who is doing the categorizing and on what basis. Though the same principles may determine the basic level, the circumstances under which those principles are employed determine what system of categories result.'

As one example of this variation grounded in similarity, we can consider category width. 'Category width refers to the tendency to classify somewhat discrepant objects in the same or different categories' (Gudykunst and Ting-Toomey, 1988, p. 162). Objects which fit into a wide category in one culture may be divided between several narrow categories in another. So while category construction is a universal process, both design and content of those categories is variable. That fact complicates attempts to map concepts from one language system onto the next.

We are finally equipped to offer a few generalizations relevant to the present investigation. Psychic unity provides the invariant algorithm by which humans construct conceptual categories. Incorporating Rosch's terms into our analogy, a generic algorithm directs humans to create categories by maximizing cue validity relative to a prototype, and by seeking to establish that prototype as the optimal point between the conflicting goals to maximize the amount of distinctiveness it recognizes in its environment while minimizing the recognized features of that environment which are irrelevant to the organism's needs. The result of the application of this algorithm is the creation of a basic level category, which is then marked linguistically by a category name such as a common noun.

The values attached to the algorithm variables can also be largely predetermined if they pertain to the small class of perceptually salient stimuli. However, most values are determined by the particular needs and interests of the language community. These experientially salient categories will be more variable cross-culturally, with a higher tendency toward idiosyncratic reference which will not be readily comprehensible to non-culture mates save to the extent that historically their needs and interests have been of the same 
sort, and ideally of the same sort in an identical environment (cf. Hunt, 1989). 'The theory of categorization,' Lakoff (1987, p. 96) concludes, 'makes predictions about what human category systems can and cannot be like. It does not predict exactly what will be in a given category in a given culture or language.'

\section{Four strategies for cross-linguistic transpositioning of verbal categories}

Equipped with a minimally detailed analysis of psychic unity as it relates to categorization, we possess the tool needed to place the acknowledged necessary miscommunication in a more explicit theoretical context. We can now, in other words, anticipate when attempted communication should be successful, or should fail through speaker incompetence, and alternatively, when that communication begins to fail regardless of the level of ability possessed by the participants.

Invoking again the image of the cultural map, intercultural communication minimally requires the transpositioning of conceptual categories as they are marked linguistically from one symbol system to another. Reading any collection of articles in this field demonstrates that this transpositioning is not the sole requirement for a successful communication event (e.g. Sajavaara, 1988). But it is hard to imagine very many nontrivial events which succeed while failing at this level. As we saw, while categories share the same structure, the content varies with the needs and interests of the language communities. Because these needs and interests vary, so too will categories, and hence, so too will the work needed to successfully effect a transposition so as to accurately convey the concept embodied by the original category in terms of the second category system.

The depiction of psychic unity allows us to predict where communication difficulties are likely to arise. Specifically, communication will be easiest to the degree that similar needs have worked to create similar conceptual categories. This principle is contained within the idea of intersubjectivity. As Giles and Coupland observed:

interactants share an array of assumptions; in fact, while it is perennially difficult to capture what is actually shared, this must be the case otherwise meaningful communication could never get off the ground....The more shared assumptions we have between us, the greater 'intersubjectivity' there will be (Giles and Coupland, 1991, p.2).

Rather than assuming that all messages are equally communicable, or that difficulties are unpredictable, psychic unity holds that there is a continuum of intersubjectivity, and hence of communicability. This continuum parallels the degree of overlap between category contents, which is itself a function of the overlap between the needs and interests of the speech communities.

At one pole are those needs which arise from the fact of biological and physical existence, motivating the creation of similar categories in all communities, and hence relatively easily to transpose (Campbell, 1964, p. 322); at the other pole will be categories which are purely idiosyncratic to a single community making distinctions which will defy all attempts at communication short of total immersion and 'going native.' One approaches this latter category with accounts such as those told of Eskimos and their many words for snow (this popular anthropological example is reviewed by Martin, 1986), or similarly, Plotkin's (1993, p. 63) discovery that the Maroons have 23 words for different river rapids. Yiddish, we are told, "has words to describe subtle gradations of the concept "simpleton" that would require entire essays in any other tongue' (Browning, 1996). Communicating these differences may well be impossible if the second party has never seen snow, experienced whitewater, or regards cleverness as a present/absent quality. 
The major points along this continuum are characterized by the types of performative strategies required to effect the transpositioning. The four we highlight are (1) translation, (2) paraphrase or interpretation, (3) explanation, and (4) evocation. By looking at these four strategies, a model can be developed which would predict in advance what can be easily and effectively communicated through direct translation, what can, with a moderate degree of difficulty be paraphrased and/or explained, what can be understood only with great difficulty by using language to evoke meanings which are nowise present in the explicit message itself, and, finally, what may remain impossible to accurately and effectively communicate interculturally.

\section{Translation}

'Translation' has been variously construed, including as the more generic change from one language system to another which we have opted to term 'transposition.' Our use of the term is restricted to the sense that it is 'a process where an expression in one language is found which is the equivalent of some expression in another language' (Harris, 1990, p. 118).

Successful translatability is determined by the degree to which labeled categories overlap between language systems. The further one moves away from empirical basic level categories (cat, sun) into abstract domains such as emotions, the less overlap will occur and the less translation becomes possible. Translation 'equivalence is a goal to be sought but never really achieved [since the] semantic spheres of translation-equivalent terms overlap to varying degrees but probably never coincide in perfection' (Osgood et al., 1975, p. 17). Prime candidates for successful translation are the 'semantic primitives' which 'are believed to have lexical exponents in all or most of the world's languages' (Goddard, 1996, p. 427). Goddard lists 'someone,' 'something,' 'people,' 'think,' 'know,' 'say,' 'feel,' 'good,' 'bad,' 'do,' and 'happen' as examples of such primitives.

An excellent discussion of this problem is given by Menachem Dagut (1981). First he operationalizes the term 'equivalence' as 'the Saussurean sense of equal linguistic "value," i.e. as the relationship existing between an item in SL (Source Language) and one in TL (Target Language), when the TL item performs as nearly as possible the same semantic function in TL as the SL item in SL' (p. 61). He next evokes a powerful image which illustrates the problem of translation:

\footnotetext{
if the vocabulary of a language is figuratively thought of as a kind of shared 'map' of its speakers' experience, with the individual designators marking the salient features of that experience as selected by the collective consciousness of the language community [as our model of psychic unity stipulates], then it is only to be expected that every lexical 'map' will be full of blank spaces....And it is also to be expected that, in most cases, the black spaces on the lexical 'map' of one language will not coincide with those on the lexical 'map' of another (Dagut, 1981, p. 63).
}

Translation can only occur when points of separate speech communities' lexical maps overlap on both the dimensions of referential denotation as well as affective connotation. This overlap can only occur when the needs which motivate categories have been sufficiently universal to apply to both communities. "If the result of a "literal translation" is that readers misunderstand what happened, it is a mistranslation, no matter how "accurately" one might claim the words correspond to the original' (Boswell, 1994, p. 19). Experiencing translation failure, the communicator must resort to another strategy.

Translation failure can often be attributed to the effects of compression. Zipf's 'Law of Abbreviation' (1935/1965) states that the more relevant and used an idea or concept is in a culture, the shorter and more specific it will become in terms of language. Conversely, the 
less an idea or concept is used in a culture, the more cumbersome it will be to describe in that culture's language. Translation fails when a condensed concept in SL has no overlapping condensed equivalent in TL.

It is always interesting to come across claims of nontranslatability, a few of which are collected here: Hall $(1959 / 1981$, p. 13) recounts complaints that Sioux has no word for time, or the concepts late and waiting; Gudykunst and Kim (1984, p. 51) claim that English has no translation for the Greek philotimos; Brazilian Portuguese has no equivalent for the phrase, 'Why won't you open the window?' (Koike, 1992, p. 69); according to Giles and Coupland (1991, p. 117), Chinese lacks common counseling words such as concern, as in 'I am concerned about you;' 'marriage' as we know it today 'quite corresponds' to nothing in the ancient world (Boswell, 1994, p. 38); 'Hebrew has no general term for 'child', sex automatically being indicated' (Osgood et al., 1975, p. 17); these same authors report that in Thai "there is no word for "brother", only "older brother" or "younger brother", (p. 30); "the concepts "wog" and "nigger" cannot be translated into Latin or Greek (Thompson, 1989, p. 4).

'Among some Indian peoples of South America, same-gender sex to orgasm is so common that their native languages do not have words for the activity' (Quinn, 1996, pp. 37 38); 'Polish does not have a word corresponding exactly to the English word disgust', while "Australian Aboriginal language Gidjingali does not seem to distinguish lexically "fear" from "shame" (Wierzbicka, 1986, p. 584); similarly, Brazilian Portuguese cannot directly translate the concept of 'dread' (Donovan, 1993, 1994, p. 638). Every reader can probably expand this list with examples from their own experience.

\section{Paraphrase}

Transpositionings can utilize paraphrases to fill those voids which exist at the level of the word, allowing more of the categories in SL to be rendered in TL. This strategy capitalizes on the fact that while overlap is not sufficient to allow translation, it is adequate to permit rough communication, although at a loss. The particular context will determine whether what is lost is relevant to the message. For instance, while philotimos cannot be translated, we are told that it suggests 'a person who follows the norms of the culture' (Gudykunst and Kim, 1984, p. 51).

Paraphrastic interpretation occurs when one takes the original message and transposes it into another system's approximate (as opposed to exact) language equivalents. Although the denotative meaning of the original language can often be preserved, rarely can all of the connotative meaning(s) of the original language also be conveyed. In keeping with our map analogy, paraphrasing would be necessary when SL and TL overlap, but when one conceptual node is larger than the other. If it is the SL node that is larger, then paraphrastic transpositioning must serve to constrict the scope within the TL. This would be the case when one word in SL could be any of several words in TL, as Burling (1984, p. 73) illustrates with the example of the English hand. If, on the other hand, it is the TL node which is larger, then paraphrasing will be required to expand it in the TL, perhaps by concatenating several proximate SL categories.

An example of the type of conceptual categories which might be paraphrased during transpositioning involves kinship. Because reproduction is biologically based, this fact serves as a small seed for a category submitted to a tremendous amount of cultural articulation. Terms for the biological nuclear family (mother, brother, father, sister) are translated easily, and in fact serve as primitives for the study of genealogies within 
anthropology. But some systems (e.g. the Hawaiian) use the same term to denote mother and mother's sister. If we use our 'aunt' to gloss Hawaiian mother's sister, we preserve the denotative reference, but we lose the social meaning backing up the indigenous term since the obligations expected of our aunts differ from what are expected from Hawaiian mother's sisters.

A recent formalization of paraphrase for purposes of scholarly standardization is Natural Semantic Metalanguage. In this method, idiosyncratic emotion terms are deconstructed into a set of sentences composed entirely of universal semantic primitives (Wierzbicka, 1986; Goddard, 1996). For instance, English anger is rendered as 'when X thinks of $Y, X$ thinks something like this: "this person did something bad; I don't want this; I would want to do something bad to this person"; because of this, X feels something bad' (Goddard, 1996 , p. 427). The intent is that eventually sets of such paraphrastic structures can be compared cross-culturally, permitting precise identification on what variables a term like anger might differ from its seemingly identical counterpart in another culture.

\section{Explanation}

We may choose to couple a paraphrase such as 'aunt' with our third strategy, an explanation or definition to explain what has been lost. This strategy is commonly resorted to in either of two circumstances. Most generally, the source concept is artificially overgeneralized so that it abuts one or more concepts within the target language. This connection made, some words are used to whittle the category back down. Operationally, the author will preserve the original source vocabulary within the text, there being no way to translate it or accurately paraphrase it. The second use of explanation is as a net to catch the meanings which fell out of the original concept when it was paraphrased into the target. Hence, while we might render the Hawaiian's mother's sister as 'aunt,' an author who wished to be accurate would include a footnote explaining the differences.

An example of explanation can be seen in the French phrase l'esprit d'escalier. In English this phrase's transliteration would be 'spirit of the stairs.' Obviously, this phrase means nothing to an English speaker beyond its literal content. A paraphrase into English would roughly correspond to the word 'afterthought,' but this rendering would also be incorrect, failing as it does to preserve the essence of the French expression. One must therefore explain the meaning: the reminiscing thoughts one has while walking down the stairs after some sort of communication engagement involving other people (e.g. a party, a business meeting, etc.).

\section{Evocation}

Finally, there is evocation, the most difficult of all the strategies. Evocation is used to summon/produce/inspire a meaning that is not itself present in the message, and partakes of Wittgenstein's distinction 'between what can be said and what can only be shown' (Dilman, 1983, p. 76). One finds it necessary to use evocation especially when the topic of the intended communication is neither a physical nor a social reality, but an emotional or a state-of-consciousness-linked reality.

Evocation can be used to deal with categories which are abstracted from real phenomena. Hence, beauty and emotions would be typical topics whose cross-cultural understanding would require evocation. Consider a statement like, 'That girl is beautiful.' Odds are good that counterparts to each of the parts of this phrase can be found in any language. The question, though, is what is tied up within the concept of 'beautiful.' While all societies 
have standards of beauty, most societies have somewhat different standards of beauty. Hence, beauty is something easier to attribute than to discuss: 'Beauty is something we praise, something we like to contemplate, and we find that it is always more than what we can say about it. Hence we often speak of beauty as "mysterious"' (Dilman, 1983, p. 72).

While Rosch reports that some emotions are probably universal, and Izard (1980) numbers these as eight based upon cross-cultural recognition of facial expressions, Wierzbicka (1986, p. 587) is more conservative, concluding that we 'simply do not know' if there are any 'emotion concepts that have been lexically recognized as distinct and identifiable in all languages of the world.' It seems doubtful, then, that all emotions exist in all cultures. Repeatedly, anthropologists are admonished about the need to learn 'new emotions' while in the field (cf. Boas, 1911, p. 98). Dilman (1983) likewise suggests that while there is a common human emotional quality (p. 154), the child must learn these as part of development (p. 111), implying that variations in learning and cultural emphasis will result in variations in emotional responses available to that individual and all similarly placed persons. Emotions do not just 'happen' (as perhaps 'feelings' might, to those who wish to split this particular hair), but rather, culture determines what one 'can want, feel and do' (p. 142). Just as there are culture-bound syndromes (Simons and Hughes, 1985), it is very likely that there are culturally unique emotional experiences as well.

Robert Levy's (1973) report on the Tahitians highlights this communication difficulty through his discussion of the problems, seemingly insurmountable, which his informants had with the concept of 'sadness.'

\footnotetext{
There are aspects of Tahitian vocabulary which represent perhaps both an expression of a situation and a control over its occurrence, in the present case a lack of a specific vocabulary for the expression of mild or moderate longing emotions. There are words for severe grief and for lamentations. There are, however, no unambiguous terms which represent the concepts of sadness, longing, or loneliness in the sense of 'depressed or sad because of the lack of friends, companionship, and so on.' People would name their condition, where I supposed that the context called for 'sadness' or 'depression,' as 'feeling troubled' (pe'ape'a, the generic term for disturbances, either internal or external); as 'not feeling a sense of inner push' (ana'anatae, inner push or enthusiasm); as 'feeling heavy' ( $t$ 'iaha); as 'feeling fatigued' (haumani); and a variety of other terms all referring to a generally troubled or subdued bodily state. These are all nonspecific terms, which had no implication of any external relational cause about them, in the sense that 'angry' implies an offense or a frustration (Levy, 1973, p. 305).
}

From this exposition, we may conclude that 'sadness,' as we use and understand the term, has no exact counterpart in the Tahitian language, precluding translation. Paraphrase might be suitable for some communicatory purposes, provided the message depends more upon a generic 'suboptimal and low energy' without requiring any details. For instance, a general understanding that you are 'just out of sorts' would do if I am seeking to understand why you were not paying attention to what I said, but not if I am seeking to understand your problem so that I can suggest possible solutions. Explanation perhaps suits academic discussions, with its vaunted objectivity, but fails to communicate what the person is really experiencing, which is the goal of most social discourse. Clinical literature is replete with the difficulties encountered by patients trying to communicate their emotional states, who usually depend heavily upon analogy with more common states, which are then intensified and conjuncted with others to create the unique mix which is being experienced by the speaker.

If the concept has a basis in reality, then at the least the object can be pointed to: that painting, there, is beautiful to me, although I cannot tell you why. Through such pointing, I can understand where you find beauty, even though I may not understand why you think that exemplar belongs in this particular category. If, however, the concept has basis 
in reality, being purely abstract, or based upon subjective states, then pointing will not suffice, and I will fail to understand what you mean.

Returning to the Tahitians, we found that they lacked a category corresponding to our 'sadness.' This in itself is unremarkable; what holds our interest, however, is the apparent difficulty Tahitians encountered when trying to learn the idea:

\footnotetext{
Fairly competent French-Tahitian bilingual speakers...did not understand the meaning of triste in its sense of 'sorrowful, mournful, melancholy, dejected' and defined its use as hamaui, 'fatigued,' or mar, 'gentle.'

\begin{abstract}
The lack of specific vocabulary does not mean that these states are inexpressible. It would be perfectly possible for a man to say something like 'I felt bad because my vahine had gone on a trip, and there was no one else in the house, and my thoughts kept turning to her.' The common way, in fact, to express that one misses an absent person is to say that one 'thinks' about him or 'thinks repeatedly' about him. It seems hard to say more than that (Levy, 1973, p. 306).
\end{abstract}

Evocation reaches a sublime form when our attention turns to religious language. Much has been written about the nature and goal of religious discourse. Our comments here are restricted to some few observations.

What does it mean to try to communicate that 'God is good'? To claim this to claim knowledge of God, which necessarily entails a mystical experience of theophany. Plato himself has held such experiences to be incommunicable (Roszak, 1980, p. 309), and Maslow (1976, p. 24) held that ritualized religions are but feeble attempts to communicate or recreate the 'original mystical experience of the original prophets.'

If it is difficult for the informant to encode the necessary information to be conveyed for communication to the anthropologist, worse still are the assertions that successful decoding can be done only by those 'who already know what you mean' (Maslow, 1976, p. 84; Fromm, 1950, p. 90, expresses a similar belief). Most damaging to the project of intercultural communication, however, is the fact that sometimes the goal of religious discourse is 'aimed at inspiration, not information' (Barrett, 1988, p. 79), where to 'understand a religious expression supposes that a passion will...follow the learning' (Holmer, 1961, p. 47). The religious pluralism evident today demonstrates utterly the failure to achieve such universal conversion, and thus, by at least this standard, for the religious communication to achieve its intended goal.

\section{Conclusions}

This article began with the unchallenged assertion that intercultural communication episodes are necessarily imperfect. The disciplinary corpus reflects the correct assumption that much of this failure is attributable to the lack of various competencies on the part of the communicants. Experts become vague, however, where the line should be drawn, if at all, beyond which increased competency will not yield improved communication.

The principle of psychic unity assures us that there will be some experiences (not many, but some) which are so far removed from the ordinary processes of categorization and conceptualization that the raw data cannot be encapsulated faithfully into language systems constructed for the communication of mundane realities. If so, limits arise as to what messages can be successfully 'encoded' in the first place. On the other hand, if an experience becomes common enough to generate a shared linguistic vocabulary in one language community, odds are that these terms and concepts can be communicated only very crudely to participants of other cultures which have not routinized that specific experience or concept, limiting what can be 'decoded.' 
The very quality which makes any communication at all possible, psychic unity, guarantees that successful communication will vary on a continuum from the universally understandable to the solipsistically incommunicable. This range will appear even in an ideal world of perfectly competent communicators. This conclusion arises because while the biological foundations of psychic unity constrain cognitive category formation so that no language system is utterly alien when compared to any other, the needs and interests of particular cultural emphases, which provide the universal process of category formation with the raw material of content for crystallization leading to lexical glossing, are necessarily variable. Divergence within limits is the result, with that divergence occurring in predictable contexts. At least some miscommunication is built into the essence of communication, and cannot be characterized as performance failure.

Many readers will have long ago accepted this necessary theoretical limit to communication success. What we have offered these scholars is an articulated foundation for this premise.

\section{REFERENCES}

Alston, W. P. (1993) The Reliability of Sense Perception. Cornell University Press, New York.

Armer, M. (1973) Methodological problems and possibilities in comparative research. In Comparative Social Research. Methodological Problems and Strategies, eds M. Armer and A. D. Grimshaw, pp. 49-79. John Wiley, New York.

Barnes, R. H. (1987) Anthropological comparison. In Comparative Anthropology, ed. L. Holy, pp. 119-134. Basil Blackwell, Oxford.

Barrett, L. E. (1988) The Rastafarians: Sounds of Cultural Dissonance (rev. edn.). Beacon Press, Boston.

Berlin, B. and Kay, P. (1991) Basic Color Terms: Their Universality and Evolution. University of California Press, Berkeley.

Bickerton, D. (1984) The language bioprogram hypothesis. Behavioral and Brain Sciences 7, $173-221$.

Boas, F. (1911) The Mind of Primitive Man. Macmillan, New York.

Boswell, J. (1994) Same-Sex Unions in Premodern Europe. Villard, New York.

Bower, B. (1997) Everybody's talkin': language's great innate debate continues to make noise. Science News 151(18), 276-277.

Brown, D. E. (1991) Human Universals. Temple University Press, Philadelphia.

Browning, J. (1996) The Rosetta hack. Scientific American 275(5), 38.

Burling, R. (1984) Learning a Field Language. University of Michigan Press, Ann Arbor.

Campbell, D. T. (1964) Distinguishing differences of perception from failures of communication in cross-cultural studies. In Cross-Cultural Understanding: Epistemology in Anthropology, eds F. S. C. Northrop and H. H. Livingston, pp. 308-336. Harper \& Row, New York.

Child, A. (1950) The sociology of perception. Journal of Genetic Psychology 77, 293-303.

Chomsky, N. (1972) Language and Mind. Harcourt Brace Jovanovich, San Diego.

Coupland, N., Wiemann, J. M. and Giles, H. (1991) Talk as 'problem' and communication as 'miscommunication': an integrative analysis. In 'Miscommunication' and Problematic Talk, eds N. Coupland, H. Giles and J. M. Wiemann, pp. 1-17. Sage, Newbury Park, CA.

Dagut, M. (1981) Semantic 'voids' as a problem in the translation process. Poetics Today 2(4), 61-71.

Dilman, I. (1983) Freud and Human Nature. Basil Blackwell, Oxford.

Donovan, J. M. (1993) Validation of a Portuguese form of Templer's Death Anxiety Scale. Psychological Reports 73, 195-200.

Donovan, J. M. (1994) Defining religion: death and anxiety in an Afro-Brazilian cult. Unpublished Ph.D. dissertation, Tulane University, New Orleans.

Frazer, J. G. (1890/1981) The Golden Bough: The Roots of Religion and Folklore. Avenel Books, New York.

Fromm, E. (1950) Psychoanalysis and Religion. Bantam Books, New York. 
Gass, S. M. and Varonis, E. M. (1991) Miscommunication in nonnative speaker discourse. In 'Miscommunication' and Problematic Talk, eds N. Coupland, H. Giles and J. M. Wiemann, pp. 121-145. Sage, Newbury Park, CA.

Giles, H. and Coupland, N. (1991) Language. Contexts and Consequences. Open University Press, Buckingham, U.K.

Goddard, C. (1996) The 'social emotions' of Malay (Bahasa Melayu). Ethos 24(3), 426-464.

Gudykunst, W. B. and Kim, Y. Y. (1984) Communicating with Strangers. An Approach to Intercultural Communication. Random House, New York.

Gudykunst, W. B. and Ting-Toomey, S. (1988) Culture and Interpersonal Communication. Sage, Newbury Park, C.A.

Hall, E. T. (1959) The Silent Language. Doubleday, New York.

Harris, R. T. (1990) Is translation possible? Diogenes 149, 105-121.

Holmer, P. L. (1961) Scientific language and the language of religion. Journal for the Scientific Study of Religion 1(1), 42-55.

Hunt, G. (1989) My logic doesn't match yours: limits to translation imposed by cognitive development. Notes on Linguistics 47, $4-25$.

Izard, C. E. (1980) Cross-cultural perspectives on emotion and emotion communication. In Handbook of CrossCultural Psychology, Volume 3: Basic Processes, eds H. C. Triandis and W. Lonner, pp. 185-221. Allyn and Bacon, Boston.

Koepping, K.-P. (1983) Adolf Bastian and the Psychic Unity of Mankind: The Foundations of Anthropology in Nineteenth Century Germany. University of Queensland Press, St. Lucia.

Koike, D. A. (1992) Language and Social Relationship in Brazilian Portuguese: The Pragmatics of Politeness. University of Texas Press, Austin.

Lakoff, G. (1987) Women, Fire, and Dangerous Things: What Categories Reveal about the Mind. University of Chicago Press, Chicago.

Leaf, M. J. (1979) Man, Mind, and Science: A History of Anthropology. Columbia University Press, New York.

Lenneberg, E. H. (1967) Biological Foundations of Language. Wiley, New York.

Levy, R. I. (1973) Tahitians: Mind and Experience in the Society Islands. University of Chicago Press, Chicago.

MacLaury, R. E. (1992) From brightness to hue: an explanatory model of color-category evolution. Current Anthropology 33(2), 137-186.

Martin, L. (1986) 'Eskimo words for snow': a case study in the genesis and decay or an anthropological example. American Anthropologist 88, 418-423.

Maslow, A. H. (1976) Religion, Values and Peak Experiences. Penguin Books, Harmondsworth, U.K.

McTear, M. F. and King, F. (1991) Miscommunication in clinical contexts: the speech therapy interview. In 'Miscommunication' and Problematic Talk, eds N. Coupland, H. Giles and J. M. Wiemann, pp. 195-214. Sage, Newbury Park, CA.

Osgood, C. E., May, W. H. and Miron, M. S. (1975) Cross-Cultural Universals of Affective Meaning. University of Illinois Press, Urbana.

Plotkin, M. J. (1993) Tales of a Shaman's Apprentice: An Ethnobotanist Searches for New Medicines in the Amazon Rain Forest. Viking, New York.

Quinn, D. M. (1996) Same-Sex Dynamics among Nineteenth-Century Americans: A Mormon Example. University of Illinois Press, Urbana.

Rosch, E. (1977) Human categorization. In Studies in Cross-Cultural Psychology, Volume 1, ed. N. Warren, pp. 1-49. Academic Press, New York.

Roszak, T. (1980) The monster and the titan: science, knowledge, and gnosis. In Introductory Readings in the Philosophy of Science, eds E. D. Klemke, R. Hollinger and A. D. Kline, pp. 305-322. Prometheus Books, Buffalo.

Sajavaara, K. (1988) Cross-linguistic and cross-cultural intelligibility. In Georgetown University Round Table on Languages and Linguistics 1987, ed P. H. Lowenberg, pp. 250-264. Georgetown University Press, Washington, D. C.

Sapir, E. (1949) Selected Writings of Edward Sapir in Language, Culture and Personality. University of California Press, Berkeley.

Simons, R. C. and Hughes, C. C. (eds) (1985) The Culture-Bound Syndromes. Folk Illnesses of Psychiatric and Anthropological Interest. D. Reidel, Dordrecht, The Netherlands. 
Thompson, L. A. (1989) Romans and Blacks. University of Oklahoma Press, Norman.

Tylor, E. B. (1878/1964) Researches into the Early History of Mankind and the Development of Civilization, ed. and abridged with an introduction by Paul Bohannan. University of Chicago Press, Chicago.

Wengle, J. L. (1988) Ethnographers in the Field: The Psychology of Research. University of Alabama Press, Tuscaloosa.

Wierzbicka, A. (1986) Human emotions: universal or culture-specific? American Anthropologist 88, 584-594.

Wiseman, R. L. and Koester, J. (1993) Intercultural Communication Competence. Sage, Newbury Park, CA.

Zipf, G. K. (1935/1965) The Psycho-Biology of Language: An Introduction to Dynamic Philology. MIT Press, Cambridge, MA. 